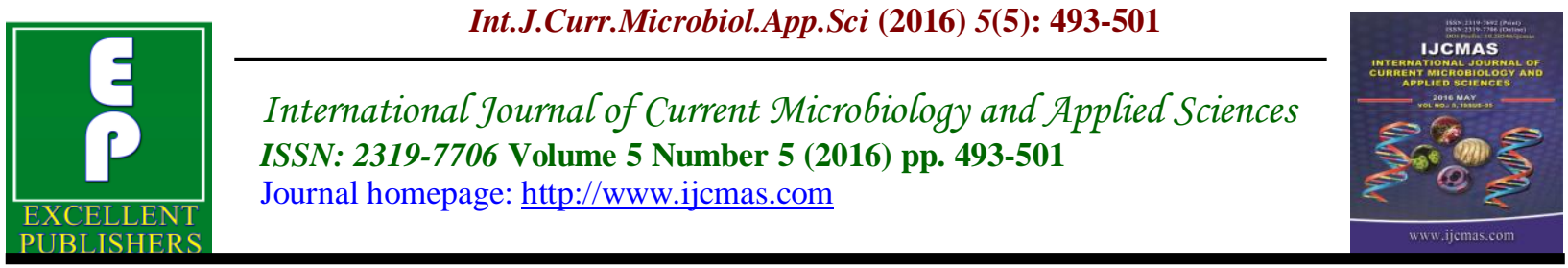

Original Research Article

http://dx.doi.org/10.20546/ijcmas.2016.505.051

\title{
Relationship between Leptin and Lipid Profile in Obese Females in Tikrit Province
}

\author{
Nawal A. Murtadha ${ }^{1^{*}}$ and Entedhar R. Sarhat ${ }^{2}$ \\ ${ }^{1}$ Dentistry College / University of Kirkuk/Iraq \\ ${ }^{2}$ Dentistry College / University of Tikrit/Iraq \\ *Corresponding author
}

\begin{abstract}
A B S T R A C T
Keywords

Leptin and Lipid profile,

Obese females, total body adiposity, hyperleptinemia.

\section{Article Info}

Accepted:

18 April 2016

Available Online:

10 May 2016

Obesity is a well Known risk factor of metabolic complications and cardiovascular disease. On the other hand, associations between anthropometric measurements and fat distribution and risk factors for cardiovascular disease have been demonstrated in several populations. To study the association of various measures of adiposity including total body adiposity (body mass index (BMI), waist circumference (WC), percentage of body fat $(\% \mathrm{BF})$, with leptin and lipid profile. To study the association between leptin and lipid profile. Serum samples collected from 129 individuals, admitted to Tikrit Teaching Hospital in Tikrit city from February 2013 to January 2014. All individuals had hormonal assay of leptin, and lipid profile, glucose. These samples were divided into three groups of according of BMI. Group 1: (Normal Weight females $n=45)$, Group 2: (Over Weight females n=46), Group 3: (Obese females $n=38$ ). The statistical analysis (students t-test) exhibited significant ( $\mathrm{P}>$ 0.0001) elevation for leptin and lipid profile (Cholesterol, Triglyceride, VLDL, LDL) while significant ( $\mathrm{P}>0.0001)$ decrease for HDL in over weight and obese groups compared with normal weight groups. The correlation coefficient (r) between Leptin and other parameters calculated with regression plot showed a positive correlation between Leptin with cholesterol, triglyceride, VLDL while a negative correlation with HDL, and paraoxonase in over weight and obese group. Circulating leptin levels appear to be one of the best biological markers of obesity and hyperleptinemia is closely associated with several risk factors related to obesity syndrome. Leptin act as atherosclerotic factors.
\end{abstract}

\section{Introduction}

In recent decades, the prevalence of obesity has increased alarmingly, making it a significant health problem in not only highincome countries, but low and middleincome countries as well (WHO, 2013). Obesity is defined as abnormal or excessive fat accumulation that presents a risk to one's health (Alexandra Manuela Stoianov, 2013).

The name of Leptin derived from the Greek Word "Leptos" meaning thin, which was originally identified in 1994 by Jeffery M. 
Friedman (Efstratiadis et al., 2007). It is a $16 \mathrm{KDa}$ protein consisting of 167 amino acid is mainly synthesized and secreted by adipocyte (Ganji et al., 2009). Serum leptin circulates either in a free or a bound form. Free leptin is thought to be the biologically active form. Its main binding protein is a circulating soluble form of leptin receptor [soluble leptin receptor (sOB-R)] which is produced by proteolytic cleavage of the short form of leptin receptor, and that sOB-R negatively regulates free leptin (Makinodan et al., 2008).

The main aim of this study includes, to investigate the associations between serum leptin levels, and lipid profile and BMI, WC and BF among obese individuals and the control group. To identify which among the metabolic parameters are closely associated with pathological levels of leptin.

\section{Materials and Methods}

A cross-sectional study was conducted from February 2013 until June 2014 among 84 obese healthy female. For the comparison, a total of 45 healthy control female without a personal history of any metabolic abnormalities were recruited to the study. The controls were taken from the same geographic areas as the patients. All subjects were randomly recruited from Tikrit Teaching Hospital in Tikrit province.

Subjects were divided into three categories of BMI (Suman et al., 2012)

Group One: - control group (Normal Weight): 45 volunteers were recruited in this group, which had a BMI ranging from 18.5 - 24.9.

Group Two: - Over Weight group: 46 volunteers were recruited in this group. Their BMIs ranging from 25.0 - 29.9.
Group Three: - Obese group: 38 volunteers were recruited in this group, Their BMIs were $\geq 30$.

\section{Anthropometric Measurements}

BMI was calculated as weight in kilograms divided by the square of height in meters. BMI= weight $(\mathrm{kg}) /$ height $(\mathrm{m}) 2$.

Waist circumference was measured in centimeters $(\mathrm{cm})$ at the end of normal expiration half way between the lowest rib and the iliac crest with the investigator standing at the side to ensure that the measuring tape is horizontal across the back and the front of the participant (WHO, 2008).

Body fat percentage: can be estimated from a person's BMI by the following formula.

Body Fat $\%=(1.2 \times$ BMI $)+(0.23 \times$ age $)-$ $5.4-(10.8 \times$ gender $)$

Where gender is equal to 0 if female and to 1 if male.

\section{Samples Collection}

From each patient and control, five $\mathrm{ml}$ of venous blood were aspirated from a suitable vein. Samples were collected between (8-9 A.M.) after 10 hours fasting. The nonheparinized blood in the plain tubes were left to clot and then centrifuged at $4000 \mathrm{rpm}$ for 5 minutes to separate the serum and stored at $-20 \mathrm{C}^{\circ}$ until assayed.

\section{Biochemical Test}

\section{Estimation of Serum Leptin}

The principle of the following immunoassay test follows a typical tow-step capture or sandwich type assay. The assay makes use 
of two highly specific monoclonal antibodies: A monoclonal antibody specific for leptin is immobilized onto the microwell plate and another monoclonal antibody specific for a different epitope of leptin is conjugated to biotin. During the first step, leptin present in the samples and standards is bound to the immobilized antibody and to the biotinylated, thus forming a sandwich complex. Excess and unbound biotinylated antibody is removed by a washing step. In the second step, streptavidin-HRP is added, which binds specifically to any bound biotinylated antibody. Again, unbound streptavidin-HRP is removed by a washing step. Next, the enzyme substrate is added (TMB), forming a blue coloured product that is directly proportional to the amount of leptin present. The enzymatic reaction is terminated by the addition of stopping solution, converting the blue color to the yellow color. Absorbance is measured on a microtiter plate reader at $450 \mathrm{~nm}$ (Check et al., 1995).

\section{Estimation of Cholesterol}

Cholesterol estimation are based either on their free fatty acids content or their cholesterol content, although measurements of the latter are more widely used, these measured enzymatically by Bio labo kit CHOD/PAP-France(Allian et al., 1974).

\section{Estimation of Triglyceride}

Determination of serum TG concentration was done by enzymatic colorimetric method using Randox kit (Randox Laboratories Ltd., UK).

\section{Estimation of HDL - Cholesterol}

Serum HDL-c concentration was determined by the precipitation method (Lopes-Virella MF1997), using HDL cholesterol /phospholipids kit supplied by Randox company (Randox Laboratories Ltd., UK),

\section{Estimation of Serum Very Low Density Lipoprotein-}

VLDL-c $(\mathrm{mmol} / \mathrm{L})=\mathrm{TG} / 2.2$.

\section{Statistical Analysis}

Statistical analysis was performed by statisticians with the SPSS 15.01 Statistical Package for Social Sciences and also Excel 2003. Data analysis was done using chisquare test for tables with frequencies, while independent sample t-test was used for tables with means and standard Deviation. $\mathrm{P}$ value of $\leq 0.05$ was used as the level of significance. Correlation coefficient used to find the correlation between studied markers by using Pearson correlation.

\section{Result and Discussion}

The mean \pm SD of age in females in the different weight groups was $(26.578 \pm 4.065$ c), (39.217 $\pm 4.022 b)$, and $(45.789 \pm 5.132 \mathrm{a})$ years, respectively.

The mean \pm SD of BMI in females in the different weight groups was $(21.620 \pm$ $1.835),(26.410 \pm 1.525)$, and (34.080 \pm $3.520) \mathrm{Kg} / \mathrm{m} 2$, respectively as in the fig(1).

The mean $\pm \mathrm{SD}$ of $\mathrm{WC}$ in females in the different weight groups was (71.000 \pm 4.596), (91.870 \pm 3.463), and(97.460 \pm 4.935) $\mathrm{Cm}$, respectively.

The mean \pm SD of $\mathrm{BF}$ in females in the different weight groups was (26.115 \pm $1.283)$, (31.779 \pm 2.772), and(37.320 \pm $2.322) \%$, respectively.

The mean \pm SD of leptin in females in the different weight groups was (7.13 \pm 3.43$),(28.89 \pm 5.42)$, and $(38.71 \pm 33.74)$ $\mathrm{ng} / \mathrm{ml}$ respectively. as in the fig(1). 
The mean \pm SD of cholesterol in females in the different weight groups was (4.4700 \pm 0.7645$),(5.1565 \pm 0.6277)$, and $(5.5179 \pm 0.8809) \mathrm{mmol} / \mathrm{l}$ respectively as in the fig(1).

The mean $\pm \mathrm{SD}$ of triglyceride in females in the different weight groups was $(1.5476$ $\pm 0.5564),(1.8868 \pm 0.4931)$, and $(2.3868 \pm$ $0.7322) \mathrm{mmol} / \mathrm{l}$, respectively as in the fig(1).
The mean \pm SD of HDL in females in the different weight groups was $(1.9000 \pm$ $0.1702),(1.7200 \pm 0.1423)$, and $(1.4900 \pm$ $0.1726) \mathrm{mmol} / \mathrm{l}$, respectively as in the fig(1).

The mean $\pm \mathrm{SD}$ of VLDL in female in the different weight groups was $(0.7030 \pm 0.1187), \quad(0.8756 \pm 0.2243), \quad$ and $(1.0840 \pm 0.2131) \mathrm{mmol} / \mathrm{l}$ respectively as in the fig (1).

Table.1 The Correlation (r) between Leptin with BMI and (Lipid profile) for Obese Groups.

\begin{tabular}{|l|c|c|}
\hline \multicolumn{3}{|c|}{ Correlation of Leptin and } \\
\hline parameters & Over weight & Obese \\
& $(\mathbf{r})$ & $(\mathbf{r})$ \\
\hline BMI & 0.124 & 0.156 \\
& & \\
\hline Cholesterol & 0.105 & 0.115 \\
\hline Triglyceride & 0.92 & 0.247 \\
\hline HDL & -0.021 & -0.115 \\
\hline VLDL & 0.061 & 0.208 \\
\hline
\end{tabular}

Fig.1 BMI levels in Normal Weight, Over Weight and Obese Groups in Females.

The mean $\pm \mathrm{SD}$ of WC in Females in the different Weight Groups was (71.000 \pm 4.596$)$, $(91.870 \pm 3.463)$, and $(97.460 \pm 4.935) \mathrm{Cm}$, respectively.

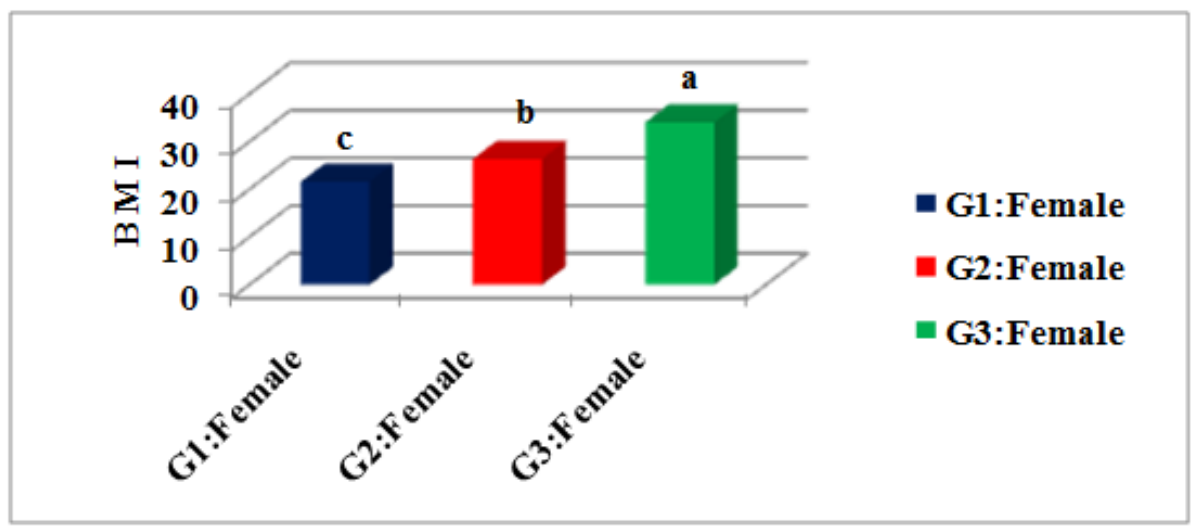


Fig.2 BMI levels in Normal Wight, Over Weight and Obese Groups in Females.

The mean \pm SD of WC in Females in the different Weight Groups was (71.000 \pm 4.596$)$, $(91.870 \pm 3.463)$, and $(97.460 \pm 4.935) \mathrm{Cm}$, respectively.

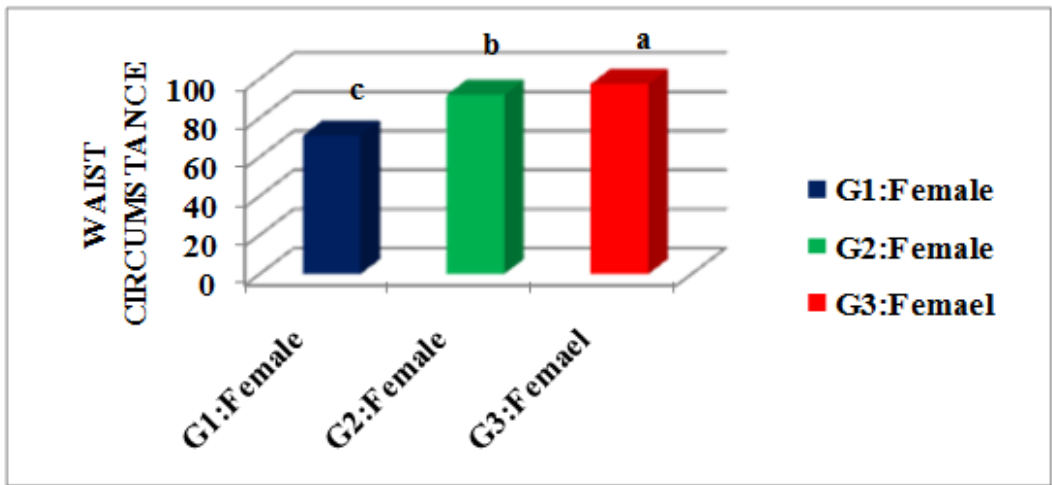

Fig.3 BMI levels in Normal Weight, Over Weight and Obese Groups in Females. The mean $\pm \mathrm{SD}$ of WC in Females in the different Weight Groups was (71.000 \pm 4.596$)$, $(91.870 \pm 3.463)$, and $(97.460 \pm 4.935) \mathrm{Cm}$, respectively.

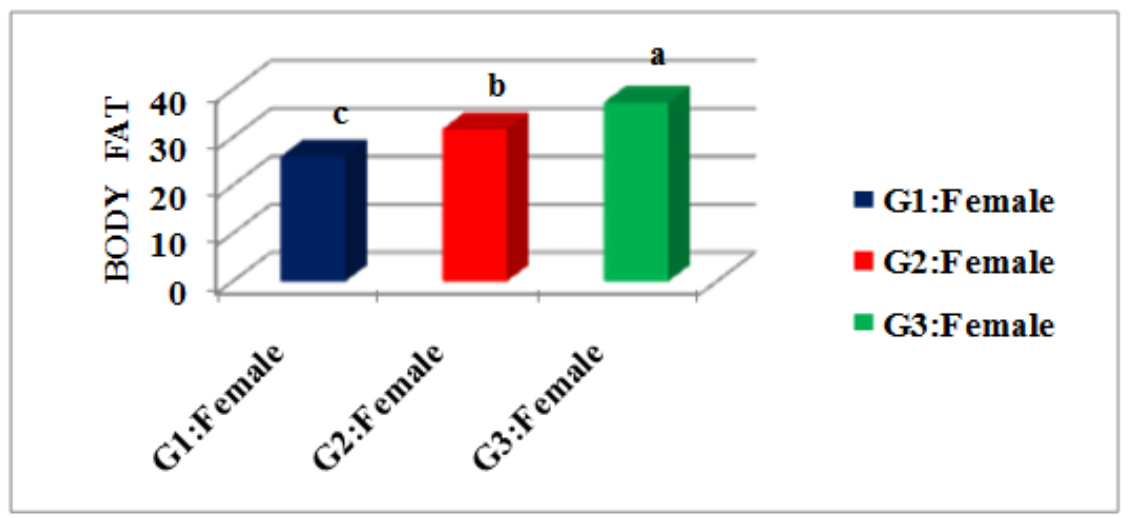

Fig.4 BMI levels in Normal Weight, Over Weight and Obese Groups in Females. The mean \pm SD of WC in Females in the different Weight Groups was (71.000 \pm 4.596), $(91.870 \pm 3.463)$, and(97.460 \pm 4.935$) \mathrm{Cm}$, respectively.

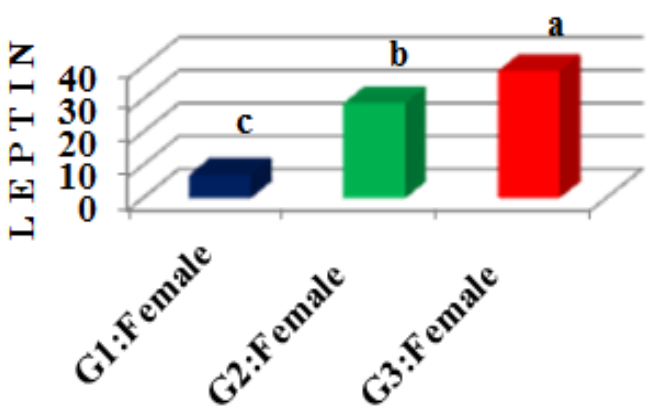

- G1:Female

G2:Female

n G3:Female 
Fig.5 BMI levels in Normal Weight, Over Weight and Obese Groups in Females. The mean \pm SD of WC in Females in the different Weight Groups was (71.000 \pm 4.596$)$, $(91.870 \pm 3.463)$, and $(97.460 \pm 4.935) \mathrm{Cm}$, respectively.

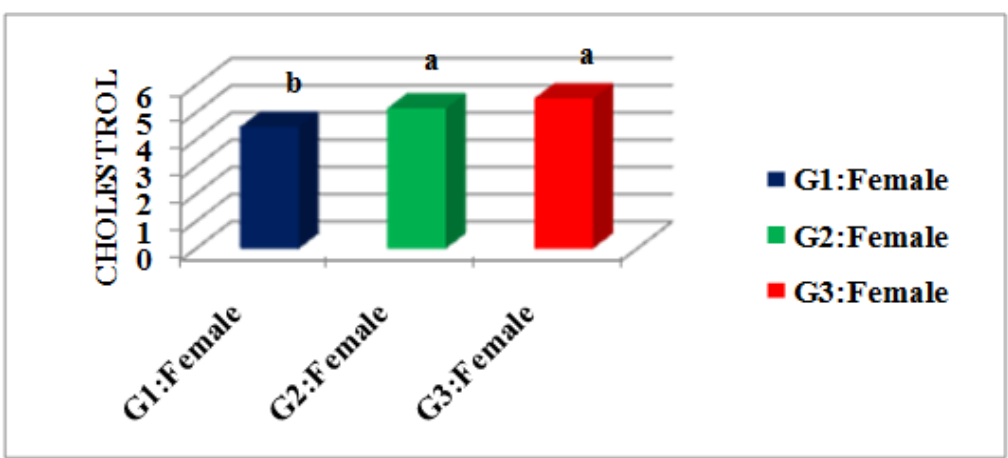

Fig.6 BMI levels in Normal Weight, Over Weight and Obese Groups in Females. The mean \pm SD of WC in Females in the different Weight Groups was (71.000 \pm 4.596$)$, $(91.870 \pm 3.463)$, and $(97.460 \pm 4.935) \mathrm{Cm}$, respectively.

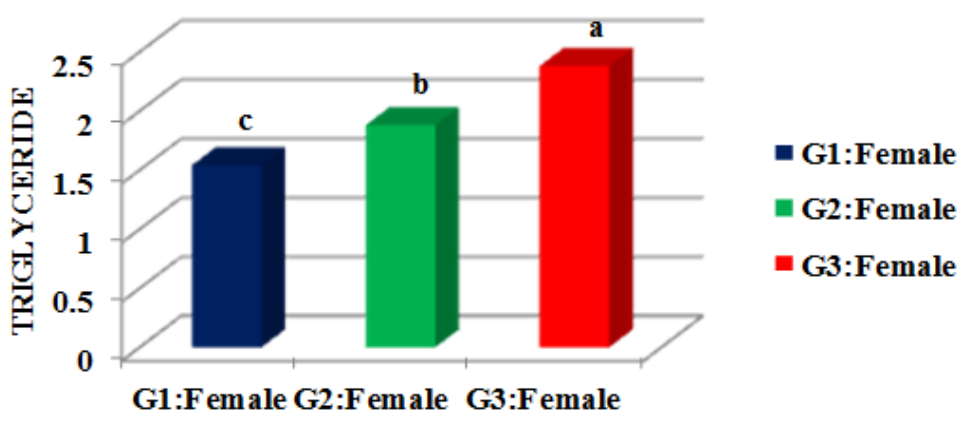

Fig.7 BMI levels in Normal Weight, Over Weight and Obese Groups in Females. The mean $\pm \mathrm{SD}$ of WC in Females in the different Weight Groups was $(71.000 \pm 4.596)$, $(91.870 \pm 3.463)$, and(97.460 \pm 4.935$) \mathrm{Cm}$, respectively.

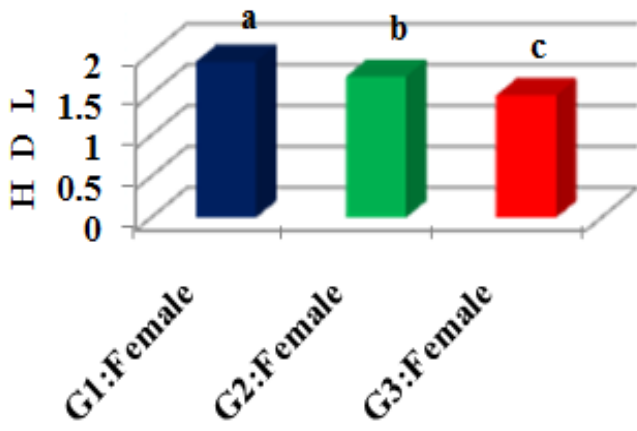

- G1:Female

G2:Female

G3:Female 
Fig.8 BMI levels in Normal Weight, Over Weight and Obese Groups in Females. The mean \pm SD of WC in Females in the different Weight Groups was (71.000 \pm 4.596$)$, $(91.870 \pm 3.463)$, and $(97.460 \pm 4.935) \mathrm{Cm}$, respectively.

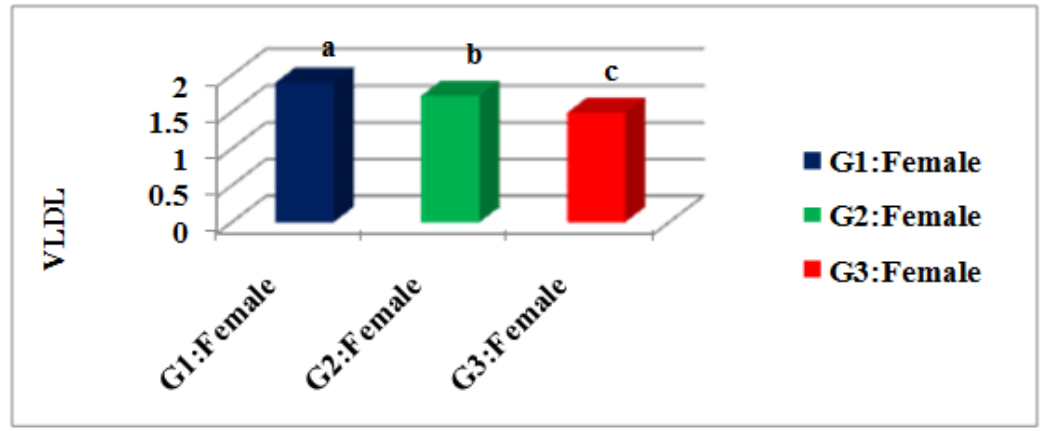

\section{Relation between Leptin, and other Parameters}

The positive correlation was found between leptin with BMI $(r=0.124)$ in over weight group, in obese group ( $\mathrm{r}=0.156)$,also with glucose in obese group $(r=0.119)$. The results showed there was positive correlation between leptin with BMI, WC BF, cholesterol, triglyceride, and VLDL in over weight group and in obese group. The negative correlation was found between leptin with HDL in obese group as in table(1).

In the present study, there was significantly higher level of leptin in overweight and obese groups compared with normal weight control group

As previous studies have reported, leptin levels were higher in obese individuals than in normal-weight individuals. Regardless of weight, leptin seems to correlate better with subcutaneous fat rather than with visceral fat in both obese and non-obese subjects. This may be due to a diminished response in the leptin receptor signalling pathway, poor penetration of the blood-brain barrier by leptin, or due to the presence of a less active molecular forms of leptin In addition, the deficient leptin in nonobese subjects as compared to obese subjects is likely to be a target for leptin therapy, whereas obese subject with high leptin levels is likely to be resistant to leptin therapy. Leptin resistance may occur directly as a result of obesity, but these may also be a lack of sensitivity to circulating leptin which could contribute to the aetiology of obesity (Adil et al., 2010).

In the present study, there is a correlation between leptin concentration and the waist circumference that is positive This is due to the close relation between BMI, WC and body fat content in addition to the responsibility of visceral and subcutaneous fat for producing leptin (Adil Omar, 2010) which is in compliance with other recent studies (De Konig et al., 2007). Leptin directly stimulates phosphorylation and activation of AMP-activated protein kinase (AMPK) in skeletal muscle, increasing phosphorylation of acetyl-CoA carboxylase (ACC) and fatty acid oxidation (at least in the early phases of AMPK activation, with later-phase activation depending on leptin functioning through the hypothalamicsympathetic nervous system axis). Although the autocrine or paracrine role of leptin in fatty acid metabolism has not yet been fully elucidated at the molecular level, it is known that leptin in adipocytes inhibits the synthesis of ACC, an enzyme essential (and rate-limiting) in the conversion of 
carbohydrates to long chain fatty acids and hence in the storage of energy as triacylglycerol. Differentiating wild-type adipocytes starved by culture in the absence of serum have lower ACC levels and lower rates of fatty acid and triacylglycerol synthesis than ob/ob cells. In addition, longterm treatment of wild-type mice with large leptin doses increases mRNA levels of the key lipolytic enzyme hormone-sensitive lipase but reduces those of the lipogenic enzyme fatty acid synthase (Francisca Lago, 2009).

Hormone-sensitive lipase levels are more immediately controlled by cellular levels of cAMP, so it seems that leptin, like glucagon and catecholamines, might stimulate lipolysis primarily by increasing cAMP concentrations. Leptin-driven control of lipid metabolism has been observed not only in adipocytes, but also in other tissues that store triacylglycerol found in lean rats. Furthermore, rats lacking functional leptin receptors have high levels of acyl-CoA synthetase and glycerol-3-PO4 acyltransferase (two enzymes required for lipogenesis), but low levels of acyl-CoA oxidase (ACO) and carnitine palmitoyl transferase I (two enzymes involved in fatty acid oxidation). This effect of leptin on lipid metabolism agrees with the results in table (3-8) this table showed that there was positive correlation between leptin and cholesterol, LDL-C, triglyceride, VLDL-C, while there was negative correlation between leptin and HDL-C.

In conclusion, Circulating leptin levels appear to be one of the best biological markers of obesity and hyperleptinemia is closely associated with several risk factors related to obesity syndrome. Leptin negatively correlated with HDL and positively correlated with total cholesterol, triglyceride, VLDL, and LDL. This relationship could make these two hormones act as atherosclerotic factors.

\section{References}

WHO. World Health Organization Fact Sheet for World Wide Prevalence of Obesity. Available online: hhtp://www.who.int/mediacentre/factsh eets/ fs311/en/indexhtml (accessed on 11 February 2013).

Alexandra Manuela Stoianov. 2013. ELONGATION FACTOR 1A-1 AND HEPATOCYTE RESPONSE TO FATTY ACID EXCESS. [MSc Thesis]. Ontario, Canada: The University of Western Ontario.

Efstratiadis, G., Nikolaidou, C., Vergoulas, G. 2007. Leptin as cardiovascular risk factor. Hippokratia, 11: 163-170.

Ganji, V., Kafai, M.R., McCarthy, E. 2009. Serum Leptin concentration are not related to dietary patterns but are related to sex,age, body mass index, serum triacylglycerol, serum insulin, and plasma glucose in the US population. Nutr. Metab., 6: 1-3.

Makinodan, k., Yoshikawa, M., Fukuoka, A., Tamaki, S., Koyama, N. Yamauchi, M., Tomoda, K., Hamada, K., Kimura, H. 2008. Effect of serum Leptin levels on Hypercaphic Ventilatory Response in obstructive sleep Apnea. Int. J. Thoracic Med., 75: 257-264.

Suman, S., Dambal, Suchetha Kumari, N. 2012. Evaluation of lipid peroxidation and totalantioxidant status in human obesity. Int. J. Institutional Pharmacy and Life Sci., 2(3): 2249-6807.

WHO. Steps Manual. Part 3 Training and Practical Guides. Geneva: WHO 2008.

Fried, M., Hainer, V., Basdevant, A. et al. 2007. "Inter-disciplinary European guidelines on surgery of severe obesity". Int. J. Obes., (Lond), 31(4): 569-77. 
Check, J., H., et al. 1995. falsely elevated sreroidal assay levels related to heterophile antibodies against various animal species. Gynecol Obstet Invest., 40: 139-140.

Allian, C.C. et al. 1974. Estimation of Serum Cholesterol. Clin. Chem., 470475.

Fossati, P., Prencipe, L. 1982. Serum triglycerides determined colorimetrically with an enzyme that produces hydrogen peroxide. Clin Chem., 28(10): 2077-2080.

Lopes-Virella, M.F., Stone, P., Ellis, S., Colwell, J.A. 1972. Cholesterol determination in high-density lipoproteins separated by three different methods. Clin. Chem., 23(5): 882-884.

Friedwald, W.T. et al. 1972. Estimation of Serum LDL-C. Clin. Chem., 18: 499.

Considine, R.V., Sinha, M.K. 2007. "serum immunoreactive-Leptin concentration in Normal Weight and Obese Humans". The New England J. Med., 13(7): 430-513.

Adil Omar Saeed Bahathiq. 2010. Relationship of Leptin Hormones with Body Mass Index and Waist Circumference in Saudi Female Population of the Makkah Community; The Open Obesity J., 2: 95-100.

De Konig, L., Merchant, A.T., Pogue, J., Anand, S.S. 2007. Waist circumference and waist-to-hip artio as predictors of cardiovascular events: meta-regression analysis of prospective studies. Eur. Heart J., 28: 850-56.

Francisca Lago, Rodolfo Go'mez, Juan J., Go' mez-Reino, Carlos Dieguez, Oreste Gualillo. 2009. "Adipokines as novel modulators of lipid metabolism." Trends in Biochem. Sci., 34(10): 501516.

\section{How to cite this article:}

Nawal A. Murtadha and Entedhar R. Sarhat. 2016. Relationship between Leptin and Lipid Profile in Obese Females in Tikrit Province. Int.J.Curr.Microbiol.App.Sci. 5(5): 493-501. doi: http://dx.doi.org/10.20546/ijcmas.2016.505.051 